\title{
Determinants of increased frequency of depressive and anxiety symptoms in exercise professionals during the COVID-19 pandemic
}

\author{
Natan Feter ${ }^{\mathrm{a}, \mathrm{b}, \mathrm{c}, \mathrm{d}, *}$, Eduardo L. Caputo ${ }^{\mathrm{a}, \mathrm{b}, \mathrm{d}}$, Igor R. Doring ${ }^{\mathrm{b}}$, Marcelo C. da Silva ${ }^{\mathrm{a}, \mathrm{b}}$, \\ Felipe F. Reichert ${ }^{\mathrm{a}, \mathrm{b}}$ and Airton J. Rombaldi $\mathrm{i}^{\mathrm{a}, \mathrm{b}, \mathrm{d}}$ \\ a Postgraduate Program in Physical Education, Federal University of Pelotas, Pelotas, Brazil \\ ${ }^{\mathrm{b}}$ GEEAF, Physical Activity Epidemiology Research Group, Pelotas, Brazil \\ ${ }^{\mathrm{c}}$ School of Human Movement and Nutrition Sciences, The University of Queensland, St Lucia, QLD, Australia \\ ${ }^{\mathrm{d}}$ Neuroscience and Physical Activity Research Group, Pelotas, Brazil
}

Received 26 April 2021

Accepted 13 July 2021

\begin{abstract}
.
BACKGROUND: The coronavirus disease (COVID-19) pandemic has affected workers in different health services including exercise professionals (EP). The urgent need to adapt in-person to online activities might have led to increased frequency of anxiety and depressive symptoms.

OBJECTIVE: We aimed to identify the determinants of aggravated depressive and anxiety symptoms in EP in southern Brazil during social distancing from the COVID-19.

METHODS: A cross-sectional study was conducted with EP who worked at fitness centers, sports clubs, private schools, or at a public exercise program offered by the municipal council. We used an online-based, self-administered, adapted version of the Hospital Anxiety and Depression scale to compare symptoms of depression and anxiety pre- and during social distancing. RESULTS: Participants $(n=201)$ had a mean age of $32.7 \pm 8.0$ years, with more than half being male, white, and having an university degree. We observed that $81 \%$ and $71 \%$ of respondents reported higher frequency in anxiety and depression symptoms, respectively, during social distancing than in the period before it. Physical education teachers, women, non-white professionals, and those with chronic disease were more likely to worsen anxiety symptoms. Women had higher odds to increased frequency in depressive symptoms. Physical activity and previous experience with internet-based tools for working activities reduced the risk of increased depressive symptoms.

CONCLUSIONS: Sex, ethnicity, chronic diseases, educational level, physical activity, and experience with online tools were determinants for increased frequency of depression and anxiety symptoms in EP.
\end{abstract}

Keywords: Physical education teachers, gym trainers, social distancing, depression, mental health, coronavirus.

*Address for correspondence: Natan Feter, School of Human Movement and Nutrition Sciences, The University of Queensland, St Lucia, QLD, 4067, Australia. Tel.: +61 0406260 878; E-mail: n.feter@uq.edu.au.

\section{Introduction}

Since the World Health Organization (WHO) declared the new coronavirus disease (COVID-19) a pandemic in March 11, 2020 [1], more than 150 million cases and three million deaths due 
to COVID-19 have been identified worldwide [2]. Disease-modifying treatments have not been developed and vaccine campaigns are yet in initial phases in some countries. Thus, non-pharmacological and simple strategies such as good personal hygiene and social distancing are among the best approaches available to reduce virus transmission and associated mortality [3-5]. Social distancing actions require interrupting all non-essential activities and services, such as schools and gyms, and cancelling sports events and concerts [4].

Social distancing might also be followed by healthrelated side effects such as poor mental health [6]. Before the COVID-19 pandemic, Brazil had the world's fifth highest prevalence of depression (9.3\%), and the world's highest prevalence of anxiety (5.8\%) [7]. Further, the Rio Grande do Sul state has the highest proportion of people with depression among all Brazilian states (13.2\%) [8]. However, data from a longitudinal study with adults from the state suggested that the proportion of adults at-risk for depression and anxiety disorders increased 6.6 and 7.4 times compared to before the pandemic [9]. Although previous data have been published about the impact of this pandemic on mental health in nurses and physicians [10-14], exercise professionals, have been disregarded by the recent COVID-19 side-effect studies.

In Pelotas, a medium size city $(\sim 320,000$ inhabitants) in the Rio Grande do Sul state, it is estimated to have 170 gyms and sports clubs and 99 private schools $[15,16]$. In this study, we considered exercise professionals as those who work at schools (as physical education [PE] teachers), gyms, and governmental projects (e.g., "Vida Ativa" project). In Pelotas, several private schools have their in-person classes suspended since March, 2020 due to the COVID19 pandemic and initiated some type of home-based classes through online activities, including PE classes [17]. Similarly, the "Vida Ativa" Project, a physical activity promotion project with 70 sites spread by the city, stopped their face-to-face activities in the same period and internet-based activities were offered. This project funded by the municipal government is target for a low-income population and offers more than 20 different exercise modalities free of charge. Regarding the fitness centers, the municipal decree published in April 22nd 2020 [18] closed temporarily all sports clubs in the city. After the next decree in May 13, sports clubs were allowed to reopen but following several restrictions, including a reduced capacity of practitioners [19].
Consequently, exercise professionals needed to adapt their classes to keep their jobs and preserve their monthly income. Thus, prescribing and monitoring exercise and PE classes through videoconference platforms and social media had to be abruptly introduced in the day-to-day professional practice. However, even such approaches do not prevent acute economic strain and work-related problems, such as job losses. Some private schools, sports clubs, and fitness centers had to dismiss some professionals due to financial issues induced by the pandemic. These problems, associated with an uncertainty about the future, might aggravate symptoms of anxiety and depression in this population. Therefore, we aimed to identify the determinants for increased frequency in depressive and anxiety symptoms in exercise professionals in southern Brazil during social distancing.

\section{Materials and methods}

\subsection{Study design}

A cross-sectional study was conducted in Pelotas, a medium size city $(344,000$ inhabitants) in the Rio Grande do Sul state, Brazil. The latest census revealed that there were 170 gyms and sports clubs and 99 private schools $[15,16]$. The study protocol was approved by the local ethics committee board (protocol no. 4.046.038).

\subsection{Sampling process}

The target population was workers with a bachelor degree in exercise science. Eligible participants were exercise science professionals who worked at fitness centers or sport clubs (hereafter referred as sports clubs), PE teachers who worked at private schools (pre-school, elementary, or high school), and professionals from a public exercise program offered by the municipal council to adults living in the city (the "Vida-Ativa" project). These three settings (gym clubs, schools or The "Vida-Ativa" project) were chosen because most of the exercise-related professionals from the city work in one of them. For example, from the 257 respondents who were exercise professionals in the city of Pelotas, $81.7 \%$ worked in some of the three settings, as shown in Fig. 1. We only selected professionals with a university degree because in Brazil it is mandatory to have such a degree to work in any of the included sectors [20]. 


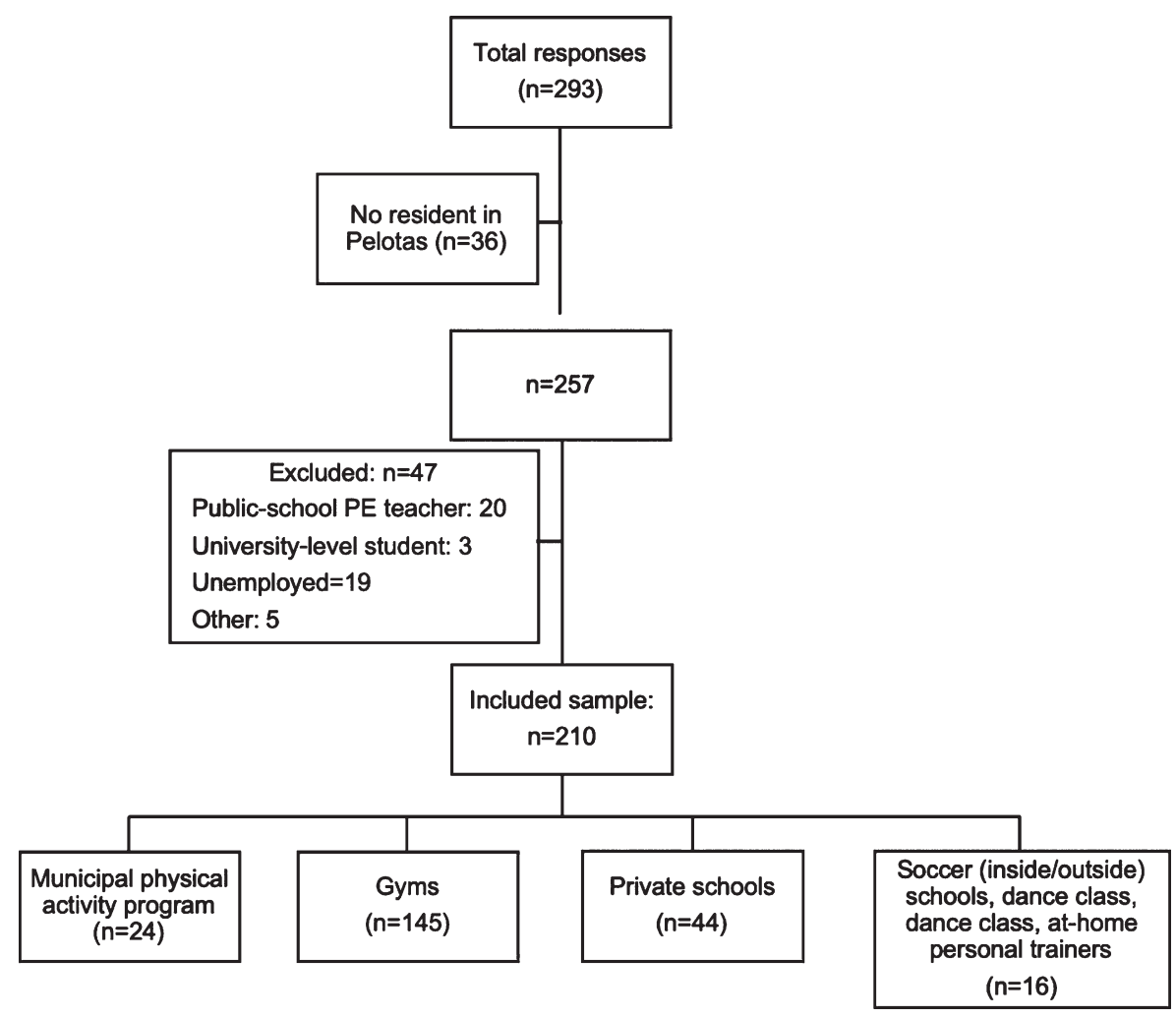

Fig. 1. Flowchart of the sampling process.

The following sampling strategy was used: First, we accessed the Regional Council of Physical Education (CREF, acronyms in Portuguese) website to identify the name and e-mail of all authorized and registered sports clubs in the city. Second, we extracted from the Regional Coordination of Education, area 5 ( $5^{\mathrm{a}} \mathrm{CRE}$, acronyms in Portuguese) website a list with all private schools in Pelotas. Both lists were imported into a Microsoft Excel ${ }^{\circledR}$ spreadsheet, so sports clubs and schools were contacted using social media (Instagram ${ }^{\circledR}$, Facebook ${ }^{\circledR}$ and WhatsApp®), e-mail, and phone call. When available, all approaches were used. Finally, the main coordinator of the "Vida Ativa" project was contacted and asked to promote the questionnaire's link via social media among all exercise professionals working in the project. To ensure participants were not able to fill the questionnaire more than once, the name and e-mail address were asked as the two first questions. Also, an independent researcher analyzed the dataset searching for duplicates but none were found.

An online-based, self-administered questionnaire to examine the effects of social distancing on depressive and anxiety symptoms was developed using
Google ${ }^{\circledR}$ Forms platform. The average time to answer the survey in a pilot study was 10 minutes, ranging from 7 to 12 minutes. During the recruitment phase (May 28th to June 21st, 2020), the social distancing restrictions were eased in the city. Then, gyms and sport clubs were allowed to open again although with reduced capacity. However, schools were still closed so PE classes were delivered by virtual activities. In-person activities of the "Vida Ativa" project were suspended during the recruitment phase. The following sections describe each questionnaire segment.

\subsection{Outcome}

Depressive and anxiety symptoms were assessed by an adapted version of the Hospital Anxiety and Depression scale (HADS) to compare symptoms of depression and anxiety pre- and during social distancing. This 14-item scale was designed to provide a simple and reliable tool for use in both community settings and primary care medical practice [21]. Each domain (i.e., depression and anxiety) has seven items and both present sufficient sensitivity (depression: 
90\%; anxiety: 88\%) and specificity (depression and anxiety: 91\%) for general population [22]. In the original questionnaire, each question scores between 0 and 3. The instrument was adapted to compare the frequency of the symptoms pre- versus during social distancing. Thus, the adapted introductory sentence was used: "Select the alternative that best describes your situation, comparing today's date with the pre-Covid-19 period". Each question had the options "More", "Equal", and "Less". Anxiety and depressive symptoms that were more frequent were scored as one. When participants reported symptoms less frequent or equal to pre-Covid-19, he or she scored 0. Questions such as "I feel happy" were scored inversely (less frequent $=1$; equal or more frequent $=0$ ). Thus, the higher the score, the higher the impact of the social distancing on depressive and anxiety symptoms. The questions used and the number of items per domain (i.e., seven questions in each domain) in the validated version were not changed to preserve the psychometric aspects of the questionnaire. For descriptive and analytical purposes, the data were operationalized as the proportion of professionals with none, one, two or three, and four or more depressive and anxiety symptoms with higher frequencies than before the pandemic. In a pilot study, fifteen exercise professionals with different backgrounds answered the adapted questionnaire twice, seven days apart. The instrument was found to be reliable given the strong correlation between answers from both assessments (Pearson's correlation coefficient: $\mathrm{r}=0.79 ; p=0.039$ ).

\subsection{Exposures}

\subsubsection{Sociodemographic and economic information}

Sociodemographic and economic information was assessed in the first part of the questionnaire. Age, gender (male, female, other/prefer do not say), ethnicity (white, black, yellow, mixed, indigenous, other), number of people living in the same household, and other professional activities were asked. The highest educational level achieved, monthly income, and the quantity and subject of complementary shortduration courses were also asked.

\subsection{Income}

Participants were asked to report the monthly income before the COVID-19 pandemic. For analysis purposes, this variable was reported as quintile intervals with the highest quintile composed by professionals with the highest monthly income.

\subsection{Professional activity}

Participants reported total time dedicated to work before and during social distancing. For analysis purposes a variable with the following categories was created: increased, no change, decreased less than $50 \%$, decreased between 50 and $74 \%$, and decreased more than $75 \%$. Although any decrease in working hours is important to be evaluated, we considered the first cut-off at $50 \%$ due to sample distribution. The next intervals at $25 \%$ might provide a dose-response relationship between the outcome and working hours changes. We also examined whether participant used any internet-based tool as an approach for PE classes or exercise training and prescription.

\subsection{Covid-19 and social distancing}

Self-rated knowledge regarding the new coronavirus (SARS-CoV-2) was rated as "bad", "regular", "good", "very good", or "excellent". For analysis purposes, we merged the two options in each extreme. Compliance with social distancing were asked by the following question: "Regarding the social distance that is being guided by health authorities, that is, staying at home and avoiding contact with other people, how much do you think you are managing to do?". The options available were "very little", "little", "somewhat", "very much", "totally isolated". The same question was used in a large, nationalbased survey of antibodies against SARS-CoV-2 in Southern Brazil [23]. As the question before, extreme categories were merged for analysis purposes.

\subsection{Physical activity}

Physical activity during social distancing was assessed by a single validated question: "In the past week, on how many days have you done a total of 30 minutes or more of physical activity, which was enough to raise your breathing rate? This may include sport, exercise, and brisk walking or cycling for recreation or to get to and from places, but should not include housework or physical activity that may be part of your job" [24]. This question presented a strong agreement to classify subjects as physically active (kappa $=0.63,95 \%$ CI 0.54 to 0.72 ) compared to a longer questionnaire (e.g., Global Physical Activity Questionnaire) [24]. Further, participants were 
classified as physically inactive or active Participants were categorized based on the latest World Health Organization guideline for physical activity [25]. The categories were none, between one and four days, and five days or more of physical activity. The latest were considered as achieving the recommendation of 150 minutes per week. This strategy was used to verify if even participants who did not achieve the recommended weekly volume of physical activity would have a reduced risk of higher frequency of depressive and anxiety symptoms.

\subsection{Chronic diseases}

Diagnosis of chronic diseases, was evaluated with the same question used in the Brazilian Surveillance System of Risk Factors for Chronic Diseases by Telephone Interviews (VIGITEL) [26]. Briefly, participants were asked whether they ever received medical diagnosis of any chronic conditions such as coronary heart disease, diabetes, hypertension, low back pain, and other.

\subsection{Data analysis}

Data were exported from Google ${ }^{\circledR}$ Sheets to a Microsoft巴 Excel spreadsheet. After cleaning process, data were imported into Stata IC 13.1. Descriptive data are reported as mean \pm standard deviation (SD) or absolute and relative values, when applicable. To identify the determinants of depressive and anxiety symptoms, crude and adjusted ordinal logistic regression was used. Coefficients were reported as odds ratio (OR) and $95 \% \mathrm{CI}$, indicating the odds of higher frequency of depressive or anxiety symptoms (none, one, two to three, four or more). Models were adjusted for sex, skin color, monthly income, educational level, physical activity, chronic diseases, change in working hours, and self-rated knowledge about Covid-19. Further, proportional OR assumption was verified by the Brant test and all variables included in the adjusted model met the criteria $(p>0.10)$.

\section{Results}

From 293 people who answered the questionnaire, $36(12.3 \%)$ were not living in the city of Pelotas, $28(9.5 \%)$ were not working in any of the included sectors (gyms/sports clubs, private schools, municipal physical activity program), and 19 (6.5\%) were unemployed at the moment of the survey. Then, 210 participants were included in the final sample. It should be noted that some participants reported to work in more than one place (e.g., sports club and private school). Sampling process is presented in Fig. 1.

Participants mean age was $32.7 \pm 8$ years, with more than half of our sample being male, white, and having an university degree as the highest educational level (Table 1). Further, 70\% did not attend to any course related to internet-based platform use to prescribe physical exercise. We also observed that $81 \%$ and $71 \%$ of our sample reported higher frequency in anxiety and depression symptoms, respectively, during social distancing restriction in comparison with the period before it.

Crude and adjusted analysis to identify the determinants of anxiety symptoms in exercise professionals during social distancing are presented in Table 2. PE teachers were more likely to report anxiety symptoms more frequently (OR: $1.91 ; 95 \% \mathrm{CI}$ : 1.04, 3.51). Also, female sex (OR: 1.67; 95\% CI: 1.03 , 2.73), non-white (OR: 1.94; 95\% CI: 1.04, 3.62), and pre-existent chronic disease (OR: $1.68 ; 95 \% \mathrm{CI}$ : $1.01,2.81)$ were associated with increased risk for more frequent anxiety symptoms. Also, we observed that participants who reported a decrease lower than $50 \%$ in working hours had lower odds to report more increased frequency of anxiety symptoms compared to the group who increased the working hours during the same period (OR: $0.19 ; 95 \%$ CI: $0.06,0.56$ ).

Table 3 illustrates crude and adjusted analysis of determinants of depression symptoms in exercise professionals during social distancing. Our findings revealed that female participants (OR: $2.60 ; 95 \% \mathrm{CI}$ : $1.55,4.36)$ had higher odds to report increased frequency of depression symptom than male. On the other hand, participants with completed specialization degree had lower odds (OR: 0.51; 95\% CI: 0.28; 0.93 ) to present increased frequency of depression symptom than university-level professionals.

Exercise professionals with previous experience in use of internet-based tool to delivery physical exercise at either gym or school settings had lower odds for increased depressive symptoms frequency (OR: $0.52 ; 95 \%$ CI: $0.30 ; 0.90)$. We revealed an inverse linear trend between physical activity and depression symptoms $(p=0.032)$, where more days of physical activity practice were associated with lower odds of reporting higher frequency in more depressive symptoms during social distancing than the period before it. 
Table 1

Sociodemographic, economic and health-related characteristics of included participants, Pelotas, Brazil. $\mathrm{N}=210$

\begin{tabular}{|c|c|c|c|c|}
\hline & $\begin{array}{c}\text { Total } \\
(n=210)\end{array}$ & $\begin{array}{c}\text { Sport clubs } \\
(n=160)\end{array}$ & $\begin{array}{l}\text { Schools } \\
(n=44)\end{array}$ & $\begin{array}{c}\text { "Vida Ativa" } \\
\text { project } \\
(n=24)\end{array}$ \\
\hline Age, mean \pm SD & $32.7 \pm 7.9$ & $32.5 \pm 7.2$ & $34.2 \pm 9.7$ & $34.5 \pm 7.2$ \\
\hline \multicolumn{5}{|l|}{ Sex, $n(\%)$} \\
\hline Male & $111(52.9)$ & $85(53.1)$ & $24(54.5)$ & $9(37.5)$ \\
\hline Female & $99(47.1)$ & $75(48.9)$ & $20(45.5)$ & $15(62.5)$ \\
\hline \multicolumn{5}{|l|}{ Skin color, $n(\%)$} \\
\hline White & $173(82.4)$ & $131(81.9)$ & $38(86.4)$ & $19(79.2)$ \\
\hline Non-white & $37(17.6)$ & $29(18.1)$ & $6(13.6)$ & $5(20.8)$ \\
\hline \multicolumn{5}{|l|}{ Income (quintile), $n(\%)$} \\
\hline 1st (poorest) & $41(20.1)$ & $32(20.7)$ & $7(16.7)$ & $8(33.3)$ \\
\hline 2nd & $43(21.1)$ & $32(20.7)$ & $7(16.7)$ & $10(41.7)$ \\
\hline $3 \mathrm{rd}$ & $51(25)$ & $41(26.5)$ & $7(16.7)$ & $3(12.5)$ \\
\hline 4th & $35(17.2)$ & $26(16.8)$ & $11(26.1)$ & $0(0.0)$ \\
\hline 5th (wealthiest) & $34(16.7)$ & $24(15.5)$ & $10(23.8)$ & $3(12.5)$ \\
\hline \multicolumn{5}{|l|}{ Other professional activity, $n(\%)$} \\
\hline No & $194(92.4)$ & $142(88.7)$ & $18(40.9)$ & $11(45.8)$ \\
\hline Yes & $16(7.6)$ & $18(11.3)$ & $26(59.1)$ & $13(54.2)$ \\
\hline \multicolumn{5}{|c|}{ Highest educational degree, $n(\%)^{*}$} \\
\hline University-level education & $106(50.7)$ & $79(49.7)$ & $17(38.6)$ & $8(33.3)$ \\
\hline Specialization & $68(32.5)$ & $53(33.3)$ & $14(31.8)$ & $13(54.2)$ \\
\hline Master/Doctoral & $35(16.7)$ & $27(17.0)$ & $13(29.6)$ & $3(12.5)$ \\
\hline \multicolumn{5}{|c|}{$\begin{array}{l}\text { Short-duration course about internet-based tools to } \\
\text { prescribe exercise, } n(\%)\end{array}$} \\
\hline No & $144(68.6)$ & $106(66.2)$ & $29(65.9)$ & $15(62.5)$ \\
\hline Yes & $66(31.4)$ & $54(33.8)$ & $15(34.1)$ & $9(37.5)$ \\
\hline \multicolumn{5}{|l|}{ Use of internet-based tools } \\
\hline \multicolumn{5}{|l|}{ Before* } \\
\hline No & $121(57.9)$ & $77(48.4)$ & $33(75.0)$ & $12(50.0)$ \\
\hline Yes & $88(42.1)$ & $82(51.6)$ & $11(25.0)$ & $12(50.0)$ \\
\hline \multicolumn{5}{|l|}{ During } \\
\hline No & $53(25.2)$ & $44(27.5)$ & $7(15.9)$ & $7(29.2)$ \\
\hline Yes & $157(74.8)$ & $116(72.5)$ & $37(84.1)$ & $17(70.8)$ \\
\hline \multicolumn{5}{|l|}{ Chronic disease } \\
\hline No & $132(62.9)$ & $102(63.7)$ & $28(63.6)$ & $17(70.8)$ \\
\hline Yes & $78(37.1)$ & $58(36.3)$ & $16(36.4)$ & $7(29.2)$ \\
\hline \multicolumn{5}{|c|}{ Physical activity during social distancing } \\
\hline None & $29(13.8)$ & $20(12.5)$ & $6(13.6)$ & $4(16.7)$ \\
\hline $1-4$ days per week & $122(58.1)$ & $95(59.4)$ & $28(63.6)$ & $15(62.5)$ \\
\hline $5+$ days per week & $59(28.1)$ & $45(28.1)$ & $10(22.7)$ & $5(20.8)$ \\
\hline \multicolumn{5}{|c|}{ Anxiety symptoms rated as more frequent, $n(\%)$} \\
\hline None & $40(19.1)$ & $31(19.4)$ & $6(13.6)$ & $6(25.0)$ \\
\hline 1 & $20(9.5)$ & $18(11.3)$ & $2(4.6)$ & $3(12.5)$ \\
\hline $2-3$ & $69(32.9)$ & $51(31.9)$ & $17(38.6)$ & $9(37.5)$ \\
\hline 4 or more & $81(38.6)$ & $60(37.5)$ & $19(43.2)$ & $6(25.0)$ \\
\hline \multicolumn{5}{|c|}{ Depressive symptoms rated as more frequent, $n(\%)$} \\
\hline None & $61(29.1)$ & $48(30.0)$ & $10(22.7)$ & $9(37.5)$ \\
\hline 1 & $61(29.1)$ & $49(30.6)$ & $11(25.0)$ & $6(25.0)$ \\
\hline $2-3$ & $62(29.5)$ & $46(28.8)$ & $14(31.8)$ & $4(16.7)$ \\
\hline 4 or more & $26(12.4)$ & $17(10.6)$ & $9(20.5)$ & $5(20.8)$ \\
\hline
\end{tabular}

SD: standard deviation; ${ }^{*} \mathrm{~N}=209$.

\section{Discussion}

To the best of our knowledge this is the first study that examined the determinants of depressive and anxiety symptoms during COVID-19 pandemic in exercise professionals. Overall, our data identify an increase in the symptoms of depression and anxiety during the pandemic time. Participants who were older, female, non-white, and with diagnosed chronic disease had higher risk for increased frequency of anxiety symptoms than their counterparts. Similarly, women had higher odds to report more depressive symptoms. On the other hand, professionals who reported practice of physical activity during social 
Table 2

Crude and adjusted association between higher frequency in anxiety symptoms and independent variables among exercise science/PE professionals, Pelotas, Brazil, 2020. ( $\mathrm{N}=210)$

\begin{tabular}{|c|c|c|c|c|}
\hline & \multicolumn{2}{|c|}{ Crude } & \multicolumn{2}{|c|}{ Adjusted } \\
\hline & $\mathrm{OR}(95 \% \mathrm{CI})$ & $p$-value & OR $(95 \% \mathrm{CI})$ & $p$-value \\
\hline Age, years & $1.01(0.97 ; 1.04)$ & $0.567^{\mathrm{a}}$ & $1.01(0.98 ; 1.05)$ & $0.370^{\mathrm{a}}$ \\
\hline Sex & & $0.056^{\mathrm{b}}$ & & $0.037^{\mathrm{b}}$ \\
\hline Male & 1.00 & & 1.00 & \\
\hline Female & $1.60(0.99 ; 2.58)$ & & $1.67(1.03 ; 2.73)$ & \\
\hline Skin color & & $0.118^{\mathrm{b}}$ & & $0.036^{\mathrm{b}}$ \\
\hline White & 1.00 & & 1.00 & \\
\hline Non-white & $1.37(0.92 ; 2.04)$ & & $1.94(1.04 ; 3.62)$ & \\
\hline Highest educational level & & $0.276^{\mathrm{a}}$ & & $0.348^{\mathrm{a}}$ \\
\hline & & $0.321^{\mathrm{b}}$ & & $0.637^{b}$ \\
\hline University-level degree & 1.00 & & 1.00 & \\
\hline Specialization & $1.02(0.60 ; 1.74)$ & & $0.89(0.48 ; 2.67)$ & \\
\hline Master/doctoral & $1.62(0.84 ; 3.12)$ & & $1.32(0.65 ; 1.65)$ & \\
\hline Monthly income, quintile & & $0.185^{\mathrm{a}}$ & & $0.217^{\mathrm{a}}$ \\
\hline & & $0.344^{\mathrm{b}}$ & & $0.549^{\mathrm{b}}$ \\
\hline 1st (poorest) & 1.00 & & 1.00 & \\
\hline 2nd & $0.54(0.25 ; 1.15)$ & & $0.63(0.28 ; 1.43)$ & \\
\hline $3 \mathrm{rd}$ & $0.63(0.31 ; 1.31)$ & & $0.78(0.36 ; 1.68)$ & \\
\hline 4th & $0.45(0.20 ; 1.00)$ & & $0.52(0.22 ; 1.23)$ & \\
\hline 5 th & $0.61(0.28 ; 1.31)$ & & $0.56(0.24 ; 1.33)$ & \\
\hline Sport clubs & & $0.108^{b}$ & & $0.613^{\mathrm{b}}$ \\
\hline No & 1.00 & & 1.00 & \\
\hline Yes & $0.63(0.36 ; 1.11)$ & & $1.22(0.56 ; 2.66)$ & \\
\hline Private schools & & $0.041^{\mathrm{b}}$ & & $0.038^{b}$ \\
\hline No & 1.00 & & 1.00 & \\
\hline Yes & $1.83(1.02 ; 3.28)$ & & $1.91(1.04 ; 3.51)$ & \\
\hline "Vida Ativa" project & & $0.375^{\mathrm{b}}$ & & $0.348^{\mathrm{b}}$ \\
\hline No & 1.00 & & 1.00 & \\
\hline Yes & $0.71(0.33 ; 1.52)$ & & $0.68(0.30 ; 1.53)$ & \\
\hline Change in working hours & & $0.011^{\mathrm{a}}$ & & $0.017^{\mathrm{b}}$ \\
\hline & & $0.017^{\mathrm{a}}$ & & $0.025^{\mathrm{b}}$ \\
\hline Increased & 1.00 & & 1.00 & \\
\hline No change & $0.45(0.14 ; 1.38)$ & & $0.43(0.14 ; 1.34)$ & \\
\hline Reduced (<less than $50 \%$ & $0.20(0.07 ; 0.59)$ & & $0.19(0.06 ; 0.56)$ & \\
\hline Reduced $(50 \%-74 \%)$ & $0.40(0.15 ; 1.05)$ & & $0.38(0.14 ; 1.03)$ & \\
\hline Reduced $(\geq 75 \%)$ & $0.60(0.23 ; 1.54)$ & & $0.54(0.21 ; 1.40)$ & \\
\hline Use of internet-based tools & & $0.264^{\mathrm{b}}$ & & $0.348^{\mathrm{b}}$ \\
\hline Before & & & & \\
\hline No & 1.00 & & 1.00 & \\
\hline Yes & $0.76(0.47 ; 1.23)$ & & $0.79(0.48 ; 1.30)$ & \\
\hline During & & $0.889^{\mathrm{b}}$ & & $0.815^{\mathrm{b}}$ \\
\hline No & 1.00 & & 1.00 & \\
\hline Yes & $0.96(0.56 ; 1.65)$ & & $0.93(0.51 ; 1.70)$ & \\
\hline Physical activity during social distancing & & $0.321^{\mathrm{a}}$ & & $0.703^{\mathrm{a}}$ \\
\hline & & $0.132^{\mathrm{b}}$ & & $0.433^{\mathrm{b}}$ \\
\hline None & 1.00 & & 1.00 & \\
\hline $1-4$ & $0.75(0.39 ; 1.48)$ & & $0.94(0.44 ; 2.00)$ & \\
\hline $5+$ & $0.56(0.26 ; 1.21)$ & & $0.75(0.33 ; 1.72)$ & \\
\hline Chronic disease & & $0.015^{\mathrm{b}}$ & & $0.047^{\mathrm{b}}$ \\
\hline No & 1.00 & & 1.00 & \\
\hline Yes & $1.86(1.13 ; 3.08)$ & & $1.68(1.01 ; 2.81)$ & \\
\hline Knowledge about COVID-19 & & $0.280^{\mathrm{a}}$ & & $0.217^{\mathrm{a}}$ \\
\hline & & $0.190^{\mathrm{b}}$ & & $0.233^{\mathrm{b}}$ \\
\hline Bad/regular & 1.00 & & 1.00 & \\
\hline Good & $0.73(0.34 ; 1.56)$ & & $0.81(0.37 ; 1.80)$ & \\
\hline Very good/ excellent & $1.16(0.55 ; 2.46)$ & & $1.28(0.59 ; 2.79)$ & \\
\hline How much are you doing social distancing? & & $0.916^{\mathrm{a}}$ & & $0.854^{\mathrm{a}}$ \\
\hline & & $0.941^{\mathrm{b}}$ & & $0.931^{\mathrm{b}}$ \\
\hline Not at all/ too little & 1.00 & & 1.00 & \\
\hline Regularly & $0.90(0.33 ; 2.46)$ & & $0.83(0.28 ; 2.48)$ & \\
\hline A lot / isolated & $0.98(0.38 ; 2.53)$ & & $0.91(0.33 ; 2.53)$ & \\
\hline
\end{tabular}

Abbreviations: OR: odds ratio; CI: confidence interval; PE: physical education. ${ }^{\mathrm{a}} p$ for heterogeneity; ${ }^{\mathrm{b}} p$ for linear trend; ${ }^{\mathrm{c}}$ Adjusted for sex, skin color, monthly income, educational level. physical activity, chronic diseases, change in working hours, and self-rated knowledge about COVID-19. 
Table 3

Crude and adjusted association between higher frequency in depressive symptoms and independent variables among exercise professionals, Pelotas, Brazil, 2020. $(\mathrm{N}=210)$

\begin{tabular}{|c|c|c|c|c|}
\hline & \multicolumn{2}{|c|}{ Crude } & \multicolumn{2}{|c|}{ Adjusted } \\
\hline & OR $(95 \% \mathrm{CI})$ & $p$-value & OR $(95 \% \mathrm{CI})$ & $p$-value \\
\hline Age, years & $1.01(0.98 ; 1.04)$ & $0.347^{\mathrm{a}}$ & $1.03(1.00 ; 1.06)$ & 0.078 \\
\hline Sex & & $<0.001^{\mathrm{b}}$ & & $<0.001$ \\
\hline Male & 1.00 & & 1.00 & \\
\hline Female & $2.49(1.51 ; 4.08)$ & & $2.60(1.55 ; 4.36)$ & \\
\hline Skin color & & $0.466^{\mathrm{b}}$ & & $0.336^{\mathrm{b}}$ \\
\hline White & 1.00 & & 1.00 & \\
\hline Non-white & $1.25(0.69 ; 2.25)$ & & $1.37(0.72 ; 2.58)$ & \\
\hline Highest educational level & & $0.625^{\mathrm{a}}$ & & $0.496^{\mathrm{a}}$ \\
\hline & & $0.096^{\mathrm{b}}$ & & $0.041^{\mathrm{b}}$ \\
\hline University-level degree & 1.00 & & 1.00 & \\
\hline Specialization & $0.73(0.42 ; 1.27)$ & & $0.51(0.28 ; 0.93)$ & \\
\hline Master/doctoral & $1.64(0.84 ; 3.20)$ & & $1.26(0.61 ; 2.60)$ & \\
\hline Monthly income, quintile & & $0.855^{\mathrm{a}}$ & & $0.808^{\mathrm{a}}$ \\
\hline & & $0.640^{\mathrm{b}}$ & & $0.223^{\mathrm{b}}$ \\
\hline 1st (poorest) & 1.00 & & 1.00 & \\
\hline 2nd & $0.88(0.41 ; 1.91)$ & & $1.17(0.52 ; 2.65)$ & \\
\hline $3 \mathrm{rd}$ & $1.28(0.62 ; 2.61)$ & & $1.70(0.80 ; 3.62)$ & \\
\hline 4th & $1.24(0.57 ; 2.69)$ & & $1.60(0.68 ; 3.74)$ & \\
\hline 5 th & $0.74(0.33 ; 1.65)$ & & $0.71(0.30 ; 1.65)$ & \\
\hline Sport clubs & & $0.109^{\mathrm{b}}$ & & $0.761^{\mathrm{b}}$ \\
\hline No & 1.00 & & 1.00 & \\
\hline Yes & $0.62(0.35 ; 1.11)$ & & $0.91(0.49 ; 1.69)$ & \\
\hline Private schools & & $0.036^{\mathrm{b}}$ & & $0.128^{\mathrm{b}}$ \\
\hline No & 1.00 & & 1.00 & \\
\hline Yes & $1.92(1.05 ; 3.53)$ & & $1.66(0.86 ; 3.18)$ & \\
\hline "Vida Ativa" project & & $0.741^{\mathrm{b}}$ & & $0.627^{\mathrm{b}}$ \\
\hline No & 1.00 & & 1.00 & \\
\hline Yes & $0.87(0.39 ; 1.95)$ & & $0.81(0.34 ; 1.90)$ & \\
\hline Change in working hours & & $0.077^{\mathrm{a}}$ & & $0.159^{\mathrm{a}}$ \\
\hline & & $0.140^{\mathrm{b}}$ & & $0.219^{\mathrm{b}}$ \\
\hline Increased & 1.00 & & 1.00 & \\
\hline No change & $0.67(0.20 ; 2.22)$ & & $0.92(0.28 ; 3.05)$ & \\
\hline Reduced (<less than $50 \%$ & $0.34(0.11 ; 1.05)$ & & $0.44(0.14 ; 1.37)$ & \\
\hline Reduced $(50 \%-74 \%)$ & $0.50(0.18 ; 1.38)$ & & $0.69(0.25 ; 1.90)$ & \\
\hline Reduced $(\geq 75 \%)$ & $0.80(0.29 ; 2.17)$ & & $1.07(0.39 ; 2.90)$ & \\
\hline Use of internet-based tools & & $<0.001^{\mathrm{b}}$ & & $0.019^{\mathrm{b}}$ \\
\hline Before & & & & \\
\hline No & 1.00 & & 1.00 & \\
\hline Yes & $0.36(0.22 ; 0.61)$ & & $0.52(0.30 ; 0.90)$ & \\
\hline During & & $0.139^{\mathrm{b}}$ & & $0.267^{\mathrm{b}}$ \\
\hline No & 1.00 & & 1.00 & \\
\hline Yes & $0.66(0.39 ; 1.14)$ & & $0.71(0.39 ; 1.30)$ & \\
\hline Physical activity during social distancing & & $0.039^{\mathrm{a}}$ & & $0.023^{\mathrm{a}}$ \\
\hline & & $0.061^{\mathrm{b}}$ & & $0.032^{\mathrm{b}}$ \\
\hline None & 1.00 & & 1.00 & \\
\hline $1-4$ & $0.38(0.18 ; 0.83)$ & & $0.36(0.16 ; 0.79)$ & \\
\hline $5+$ & $0.37(0.16 ; 0.84)$ & & $0.32(0.13 ; 0.75)$ & \\
\hline Chronic disease & & $0.098^{\mathrm{b}}$ & & $0.362^{\mathrm{b}}$ \\
\hline No & 1.00 & & 1.00 & \\
\hline Yes & $1.52(0.92 ; 2.53)$ & & $1.28(0.75 ; 2.19)$ & \\
\hline Knowledge about COVID-19 & & $0.285^{\mathrm{a}}$ & & $0.223^{\mathrm{a}}$ \\
\hline & & $0.517^{\mathrm{b}}$ & & $0.442^{\mathrm{b}}$ \\
\hline Bad/regular & 1.00 & & 1.00 & \\
\hline Good & $0.72(0.33 ; 1.53)$ & & $0.69(0.30 ; 1.57)$ & \\
\hline Very good/ excellent & $0.64(0.30 ; 1.36)$ & & $0.60(0.27 ; 1.32)$ & \\
\hline How much are you doing social distancing? & & $0.429^{\mathrm{a}}$ & & $0.401^{\mathrm{a}}$ \\
\hline & & $0.726^{\mathrm{b}}$ & & $0.642^{\mathrm{b}}$ \\
\hline Not at all/ too little & 1.00 & & 1.00 & \\
\hline Regularly & $1.19(0.44 ; 3.25)$ & & $1.08(0.37 ; 3.20)$ & \\
\hline A lot / isolated & $1.38(0.56 ; 3.45)$ & & $1.38(0.50 ; 3.81)$ & \\
\hline
\end{tabular}

Abbreviations: OR: odds ratio; CI: confidence interval; PE: physical education. ${ }^{\mathrm{a}} p$ for heterogeneity; ${ }^{\mathrm{b}} p$ for linear trend; Adjusted for sex, skin color, monthly income, educational level. physical activity, chronic diseases, change in working hours, and self-rated knowledge about COVID-19. 
distancing and with specialization degree presented lower risk for higher frequency of anxiety symptoms. Previous experience in internet-based tools for professional activity before COVID-19 pandemic reduced the odds for more depressive symptoms compared to participants with no previous practice.

Exercise professionals in Brazil had to change the way that physical activity in either gyms or schools setting were prescribed. Due to social distancing, there was a need to use internet-based tools such as WhatsApp ${ }^{\circledR}$ and Facebook ${ }^{\circledR}$ in work-related activities $[27,28]$. However, only $42.1 \%$ of participants had used such platforms before COVID-19 pandemic, with lower proportion in PE teachers (25\%). This abruptly need of change in working strategies, along with the social and economic impact of the pandemic in countries such as Brazil, might have contributed to the increased frequency of depressive symptoms in this population especially among PE teachers. We revealed that professionals with previous experience in internet-based tools in work-related activities had lower risk for higher frequency of depression symptoms. This may be associated with a reduced effort for these professionals to adapt themselves to the "new" working reality, resulting in less struggle to manage and delivery exercise class during social distancing restrictions.

Furthermore, in the same model, we revealed that physical activity was associated with a reduced risk for higher frequency of depressive symptoms in exercise professionals. In previous studies, we suggested that physical activity before and during the social distancing induced by the COVID-19 pandemic reduces the risk of aggravated anxiety and depressive symptoms [9] and subjective memory decline [29]. Physical activity is a known protective agent against both depression [30, 31] and anxiety [31, 32]. Although is beyond the scope of this study, some of the biological mechanisms that may be related to this protective association are the increase in availability of serotonin, norepinephrine, and endorphin, decreased inflammatory and oxidative stress markers [33]. Then, home-based physical activity must be promoted in this population to mitigate the detrimental effects of COVID-19 pandemic on mental health.

Participants who were women, non-white, and had any pre-existent chronic disease reported higher risk for more anxiety symptoms than before the COVID19 pandemic. Previous studies observed that female sex [34] and low educational level [35, 36] were associated with an increased risk of depression. Likewise, in a large population-based survey, age, female sex, and chronic diseases were also determinants for worse anxiety and depressive symptoms [9], corroborating the findings from the present study. Similarly, in a survey conducted in India, two thirds of women reported being stressed during the pandemic period compared to $34 \%$ of men [34]. Due to gender inequality in household activities, many women might be facing increased demand from daily tasks such as home schooling and caring older people, which made the World Health Organization classify them as a high-risk group for impaired mental health during COVID-19 pandemic [37].

Further, the latest National Health Survey conducted in Brazil revealed that $79 \%$ of people with depression did not receive any type of treatment. Further, white subjects are more likely to have access to treatment than non-white individuals [38]. However, during COVID-19 pandemic healthcare systems particularly in low- and middle-income countries are disrupted [39]. For example, people with depression are more likely to have impaired access to prescribed medicines during social distancing in Brazil [40]. Further, people are afraid to get out their home and seek for health care due to fear of contagious by SARS-CoV-2 [40], increasing the risk for untreated mental disorders such as anxiety and depression. Strategies to reduce inequality in treatment for mental health disorders are urgently needed in order to reduce the burden of COVID-19 pandemic on mental health.

Some important limitations of the present study need to be acknowledged. First, the use of the modified HADS must be highlighted. A modified version of the HADS was applied, otherwise the participants would need to complete the HADS twice (one section relaying on the before Covid-19 period and another on the moment the survey was taken). The latest would be more time demanding for the respondent increasing the risk of non-respondent bias. Interpretation of the present findings deserves caution as there are limitations inherent to an online, self-reported survey during the COVID-19 pandemic [41]. Second, memory bias is a concern, since participants were asked to compare the frequency of symptoms of depression and anxiety between the current period with the period before social distancing restrictions. However, COVID-19 is the greatest global sanitary crisis in our time and given magnitude and singularity of this moment, it is likely that individuals remember how their lives before the pandemic were. Third, the websurvey did not allow us to calculate losses and refusals, thus we cannot rule out the risk of selection 
bias [41]. Fourth, the cross-sectional design does not allow us to draw causal relationship. Notwithstanding our limitations, exercise professionals are considered health professionals, acting in both prevention and treatment of communicable and non-communicable diseases. This population needs to be included when analyzing the impact of COVID-19 in healthcare workers.

\section{Conclusion}

We concluded that sex, ethnicity, presence of chronic diseases, educational level, change in working hours, and physical inactivity were determinants for increased frequency of symptoms of depression and anxiety in exercise professionals. Further, we revealed that participants with previous experience in use internet-based tools in working setting have lower odds for depressive symptom compared to those who not have used these tools before COVID19 pandemic. Although our findings bring light to the discussion on the impact of COVID-19 pandemic in exercise professionals, studies with longitudinal design are warranted to confirm or refuse our conclusions.

\section{Acknowledgments}

This study was financed in part by the Coordenação de Aperfeiçoamento de Pessoal de Nível Superior Brasil (CAPES) - Finance Code 001.

\section{Conflict of interest}

None to declare.

\section{References}

[1] World Health Organization (WHO). Coronavirus disease 2019 (COVID-19) situation report-51. Geneva, Switzerland: World Health Organization; 2020. 2020.

[2] Dong E, Du H, Gardner L. An interactive web-based dashboard to track COVID-19 in real time. Lancet Infect Dis. 2020;20(5):533-4.

[3] Arshad Ali S, Baloch M, Ahmed N, Arshad Ali A, Iqbal A. The outbreak of Coronavirus Disease 2019 (COVID19)-An emerging global health threat. J Infect Public Health. 2020;13(4):644-6.

[4] Wilder-Smith A, Freedman DO. Isolation, quarantine, social distancing and community containment: pivotal role for old-style public health measures in the novel coronavirus (2019-nCoV) outbreak. J Travel Med. 2020;27(2).

[5] Nussbaumer-Streit B, Mayr V, Dobrescu AI, Chapman A, Persad E, Klerings I, et al. Quarantine alone or in combination with other public health measures to control COVID-19: a rapid review. Cochrane Database Syst Rev. 2020;(4).

[6] Paules CI, Marston HD, Fauci AS. Coronavirus InfectionsMore Than Just the Common Cold. Vol. 323, JAMA Journal of the American Medical Association. American Medical Association; 2020;707-8.

[7] World Health Organization (WHO). Depression and other common mental disorders: global health estimates. World Health Organization; 2017.

[8] Stopa SR, Malta DC, Oliveira MM de, Lopes C de S, Menezes PR, Kinoshita RT. Prevalência do autorrelato de depressão no Brasil: resultados da Pesquisa Nacional de Saúde, 2013. Rev Bras Epidemiol. 2015;18:170-80.

[9] Feter N, Caputo EL, Doring IR, Leite JS, Cassuriaga J, Reichert FF, et al. Sharp increase in depression and anxiety among Brazilian adults during the COVID-19 pandemic: findings from the PAMPA cohort. Public Health. 2021; 190:101-7.

[10] Pappa S, Ntella V, Giannakas T, Giannakoulis VG, Papoutsi E, Katsaounou P. Prevalence of depression, anxiety, and insomnia among healthcare workers during the COVID-19 pandemic: A systematic review and meta-analysis. Brain Behav Immun. 2020;

[11] Spoorthy MS, Pratapa SK, Mahant S. Mental health problems faced by healthcare workers due to the COVID-19 pandemic-A review. Asian J Psychiatr. 2020;51:102119.

[12] Vindegaard N, Benros ME. COVID-19 pandemic and mental health consequences: systematic review of the current evidence. Brain Behav Immun. 2020;

[13] Arca M, Dönmezdil S, Durmaz ED. The effect of the COVID-19 Pandemic on anxiety, depression, and musculoskeletal system complaints in healthcare workers. Work. 2021;(Preprint):1-8.

[14] Lazarides AL, Belay ES, Anastasio AT, Cook CE, Anakwenze OA. Physician burnout and professional satisfaction in orthopedic surgeons during the COVID-19 Pandemic. Work. 2021;(Preprint):1-8.

[15] Hartwig T, Silva M, Reichert F, Rombaldi A. Condições de saúde de trabalhadores de academias da cidade de PelotasRS: um estudo de base populacional. Rev Bras Atividade Física Saúde. 2012;17(6):500-11.

[16] Coordenação Regional de Educação (CRE). CADASTRO DE ESTABELECIMENTOS DE ENSINO - REDE PARTICULAR - RS 2017 [Internet]. 2020. p. 1-35. Available from: https://educacao.rs.gov.br/busca-de-escolas.

[17] Prefeitura Municipal de Pelotas. Decreto $\mathrm{n}^{\circ} 6.249$, de 17 de março de 2020. [Internet]. Pelotas; 2020. Available from: http://pelotas.rs.gov.br/noticia/prefeitura-apresentamedidas-para-prevencao-contra-o-novo-coronavirus.

[18] Prefeitura Municipal de Pelotas. Decreto n ${ }^{\circ} 6.267$, de 22 de abril de 2020. 2020.

[19] Prefeitura Municipal de Pelotas. Decreto n ${ }^{\circ} 6.276$, de 13 de maio de 2020. Pelotas; 2020.

[20] República Federativa do Brasil. Lei ${ }^{\circ}$ 9.696, de 1 de setembro de 1998. [Internet]. 1998. Available from: http:// www.planalto.gov.br/ccivil_03/leis/19696.htm\#: :text=L969 6\&text=LEI N ${ }^{\circ} 9.696 \% 2 \mathrm{C}$ DE 1,Conselhos Regionais de Educação Física.

[21] Snaith RP. The hospital anxiety and depression scale. Health Qual Life Outcomes. 2003;1:29. 
[22] Bjelland I, Dahl AA, Haug TT, Neckelmann D. The validity of the Hospital Anxiety and Depression Scale: an updated literature review. J Psychosom Res. 2002;52(2):69-77.

[23] Barros AJD, Victora CG, Menezes A, Horta BL, Hartwig F, Victora G, et al. Social distancing patterns in nine municipalities of Rio Grande do Sul, Brazil: the Epicovid19/RS study. Rev Saude Publica. 2020;54:75.

[24] Milton K, Bull FC, Bauman A. Reliability and validity testing of a single-item physical activity measure. Br J Sports Med. 2011;45(3):203-8.

[25] Bull FC, Al-Ansari SS, Biddle S, Borodulin K, Buman MP, Cardon G, et al. World Health Organization 2020 guidelines on physical activity and sedentary behaviour. Br J Sports Med [Internet]. 2020;54(24):1451 LP - 1462. Available from: http://bjsm.bmj.com/content/54/24/1451.abstract

[26] Enes CC, Nucci LB. A Telephone Surveillance System for Noncommunicable Diseases in Brazil. Public Health Rep. 2019;0033354919848741.

[27] Brant R, Mourão HC. DESAFIOS DO TELETRABALHO NA PANDEMIA COVID-19: QUANDO O HOME VIRA OFFICE. Cad Adm. 2020;28(Edição E):71-5.

[28] Fadinger H, Schymik J. The costs and benefits of home office during the covid-19 pandemic: Evidence from infections and an input-output model for germany. COVID Econ Vetted Real-Time Pap. 2020;9:107-34.

[29] Feter N, Caputo EL, Smith EC, Doring IR, Cassuriaga J, Leite JS, et al. Association between physical activity and subjective memory decline triggered by the COVID19 pandemic: Findings from the PAMPA cohort. Prev Med (Baltim). 2021;106415

[30] Stubbs B, Koyanagi A, Schuch FB, Firth J, Rosenbaum $\mathrm{S}$, Veronese $\mathrm{N}$, et al. Physical activity and depression: a large cross-sectional, population-based study across 36 lowand middle-income countries. Acta Psychiatr Scand. 2016; 134(6):546-56.

[31] Dunn AL, Trivedi MH, O'Neal HA. Physical activity doseresponse effects on outcomes of depression and anxiety. Vol. 33, Medicine \& Science in Sports \& Exercise. US: Lippincott Williams \& Wilkins; 2001. p. S587-97.
[32] Schuch FB, Stubbs B, Meyer J, Heissel A, Zech P, Vancampfort $\mathrm{D}$, et al. Physical activity protects from incident anxiety: A meta-analysis of prospective cohort studies. Depress Anxiety. 2019;36(9):846-58.

[33] Schuch FB, Deslandes AC, Stubbs B, Gosmann NP, da Silva CTB, de Almeida Fleck MP. Neurobiological effects of exercise on major depressive disorder: a systematic review. Neurosci Biobehav Rev. 2016;61:1-11.

[34] Fund UNP. New UNFPA projections predict calamitous impact on women's health as COVID-19 pandemic continues. 2020.

[35] Wang C, Pan R, Wan X, Tan Y, Xu L, McIntyre RS, et al. A longitudinal study on the mental health of general population during the COVID-19 epidemic in China. Brain Behav Immun. 2020;

[36] Qiu J, Shen B, Zhao M, Wang Z, Xie B, Xu Y. A nationwide survey of psychological distress among Chinese people in the COVID-19 epidemic: implications and policy recommendations. Gen psychiatry. 2020;33(2).

[37] United Nations (UN). COVID-19 and the Need for Action on Mental Health [Internet]. Policy Brief. 2020. Available from: https://unsdg.un.org/resources/policy-brief-covid19-and-need-action-mental-health.

[38] Lopes CS, Hellwig N, e Silva G de A, Menezes PR. Inequities in access to depression treatment: results of the Brazilian National Health Survey-PNS. Int J Equity Health. 2016;15(1): 154 .

[39] World Health Organization (WHO). Rapid assessment of service delivery for NCDs during the COVID-19 pandemic. Geneva World Heal Organ. 2020;

[40] Leite, J.S, Feter, N, Caputo, E.L, Doring, I.R, Cassuriaga, J, Reichert, F.F, Silva, M.C, Rombaldi AJ. Managing noncommunicable diseases during the COVID-19 pandemic in Brazil: findingsthe PAMPA cohort. Cien Saude Colet. 2020;

[41] Caputo EL, Feter N, Rombaldi AJ, da Silva MC, Reichert FF. What are the challenges of epidemiological research during the COVID-19 pandemic? Mot Rev Educ Física. 2021;27. 